\title{
The Origin and Development of Teahouse Culture
}

\author{
Hongguang Ge \\ School of Management \\ Harbin University of Science and Technology \\ Harbin, China 150040
}

\author{
Guowei Zhao \\ School of Management \\ Harbin University of Science and Technology \\ Harbin, China 150040
}

\begin{abstract}
The paper analyzes the origin and development of teahouse culture by analyzing the Chinese teahouse culture in different periods, the evolution of teahouse cultural function and the description of teahouse style and expect that Chinese teahouse industry can develop better.
\end{abstract}

Keywords—teahouse culture; origin; development

\section{INTRODUCTION}

Teahouse is a special place for Chinese people to drink tea. People also can enjoy themselves, buy and sell thing and discuss things here, so it is suitable for both the old and the young, male and female. When guests come here, they order a pot of tea and then chat together. How comfortable it is to drink and chat here! In teahouse, people all over the country are brothers. They drink and talk about national affairs, housewifery and things in heart. So teahouse can be called a concentrated society.

Teahouse, this name mainly appeared in the Yangtze River area. While in Guangdong, Guangxi and Hunan province, it was called tea building. In western places such as Beijing and Tianjin, teahouse also named tea pavilion. In the history record, there were some names such as tea shop, tea room, tea market, Tiffin, tea club, tea hall and tea garden. In spite of different names, they have same patterns and practices.

\section{Historical DeVelopment OF TEAHOUSE CUlture}

Tea Ching, written by $\mathrm{Lu} \mathrm{Yu} \mathrm{in} \mathrm{Tang} \mathrm{dynasty,} \mathrm{puts,} \mathrm{"as} \mathrm{a}$ kind of drink, tea was initially used at Shennong stage while it was recorded from Zhou dynasty". [1] This proved that the tea originated from prehistoric Shennong stage. Shennong was a legendary person who invented agriculture and medicine five thousand years ago. It was said that he tasted hundreds of kinds of drug herbs and many of them were poisonous, while he was cured by tea [2]. Therefore, the history of tea in China has been more than five thousand years.

\section{A. The Burgeon of Teahouse}

Teahouse in China has a long history. There was a fairy story in The Biography of the Elders in Guangling District (Today Yangzhou). "In Jin dynasty (317-322), an old lady sells tea on the market every day and many people buy it. She sells day after day, never stop"[3]. This is exactly similar to today's tea stall.

\section{B. The Rise of Teahouse}

The early form of teahouse appeared in the Kaiyuan years of Emperor Xuanzong in Tang dynasty. In the late Tianbao years, former third degree candidate Feng Yan recorded in the sixth chapter in his book The Record of What Mr. Feng Sees and Hears that: "in the middle of Kaiyuan years, there was a master who can vanquish monsters at Lingyan temple in Taizhou, he advertised Zen Buddhism greatly. When learning Zen Buddhism, the monks were not allowed to doze or have dinner, they were only allowed to drink tea. So they brought tea to anywhere they arrived and spoiled tea and drunk there. People there imitated the monks and begun to drink tea, so it became a custom. From Zou, Qi, Cang, Li, Jian to the hospital, teahouse appeared in many towns and people sold tea here. Both monks and laymen bought and drunk it. The shops in streets are the early form of teahouse.

The Old Tang History · Biography of Wang Ya recorded that: "in the ninth year of Taihe, Wang Ya escaped in a hurry, and he was captured by soldiers at a tea house in Yongchangli". So in the Taihe years of Emperor Wenzong in Tang dynasty, there was formal teahouse.

In the middle stage of Tang dynasty, the stable politics of the country, unprecedentedly prosperous social economy as well as the publication of Tea Ching by Lu Yu made people all over the country increasingly drink Tea. Therefore, teahouse popularized rapidly in the south of the lower reaches of the Yangtze River where produce tea and spread to northern cities. At the time, besides providing tea, the teahouse can be a rest place and restaurant for people.

\section{The Prosperity of Teahouse}

In song dynasty, cities and towns became popular. In prosperous market, people did businesses day and night, which provided a good opportunity for the development of teahouse, and Independent operation begun to appear. People also could consult here, make deals, and discuss something leisurely as well as play and sing for fun in teahouse, so the role of tea for interpersonal communication began to emerge. At that time, there was a teahouse named Congxingjiao in the east of Panlou in Kaifeng and Beishanzi teahouse at Caomen Street, this kind of teahouse not only provided tea for people, but also created a private place, which made the guests inebriated. In song dynasty, teahouse was not only popular in Kaifeng, but also appeared in kinds of cities and towns. The classical masterpiece Water Margin, which reflected the song dynasty peasant uprising, also described that lady Wang opened a 
teahouse. Biography of Agriculture and Riverside Scene at Qingming Festival also presented the real scene of that time lively, and the teahouse culture became a rising mark of tea cultue for citizens in Song dynasty.

\section{The Popularization of Teahouse}

In Ming dynasty, it was recorded in Beautiful Memories at Tao Hut written by Zhang Dai that: "in Chongzhen decyl unitary year (1633), someone opened a teahouse, the water came from Yudai Beach while tea was Lanxue tea. All of the hot water was boiled lately and all the utensils were washed immediately after using, so the heating temperature and standards for heating water also had something with the weather". This showed that teahouse had developed to some extent at that time and had been on sale. The tea was demanding on tea leaves, water, tools, making process and heating process, so the owners can attract customers. At the same time, the big bowl tea industry emerged in Beijing, and it was listed in 360 kinds of formal industries.

The teahouse in the Qing Dynasty has a new development. In Kang-Qian Flourishing Age, teahouse collected the advantages of former generations and showed a magnificent view in many aspects such as number, type and function. At this time, the owners not only paid great attention to environment of the teahouse, but also provided snacks for customers. During the reign of Emperor Qianlong, the famous teahouse "Hongfu Garden" and "Chunhe Garden" in the south of the Yangtze River were all in the east of Wenxingge and took a place in the market. Customers appreciated water on the railing, talking over tea. They provided Yunwu, Longjing, Meipian, Maojian and so on, and the guests can choose whatever they like. They also supplied melon seeds, Chinese style baked roll, spring rolls, crystal cake and other refreshments, so the customers can enjoy themselves. In addition to daily tea, people had also held four large-scale activities named "thousand old man feast" in the Qing dynasty. The emperor Qianlong reign, who could not live a day without tea, in the last year of his region, called more 3000 living officials to present this grand gathering, writing poetry and drinking tea together.

In Qing dynasty, Beijing teahouse can be divided into three categories: one kind of the teahouses also sold food, it is somewhat similar to the restaurant in Guangdong. Guests can eat and drink here. Names of these teahouses commonly have the word Tian such as "Tianfu, Tianlu, Tiantai and Tiande", etc. The seats are spacious, bright and clean, with elegant furnishings and elegant tea sets, so this kind of teahouse is of the first class. Other kind of teahouse only sells tea, but customers can communicate by hands (playing chess such as the game of go and Chinese chess), and by pen (guessing riddles). There are also some specialized entertainers storytelling and singing here. The last kind teahouse located in the outskirts, on the roadside or under the shade of the tree. Although they have soil stools, provide plain pottery bowls, people drinking tea, show a field flavor.

\section{E. Decline and Revival of Teahouse}

Modern Chinese history was a messy and tragic music. It was from the Opium War in 1840 to the beginning of the "May
Fourth" cultural movement in 1919. During this period, the society was unrest, full of wars and sharp contradictions. All of these resulted in the decline of Chinese tea industry. At this time, teahouse became a place for people to understand the current situation, forecast the development of the situation and get a variety of information and even became the storeroom for capitalist aggressors to accommodate opium, cigarettes and bullets. During the period of the Republic of China, the teahouse was further developed. It displayed various functions such as "the combination of teahouses and restaurants, the combination of teahouses and grocery stores, the combination of teahouses and chess, the combination of teahouses and playing cricket. Many forms of business formed different characteristics of the teahouse, attracting different levels of guests to the teahouse for consumption, making a good preparation for the rise of Tea Culture Center.

Modern Tea Culture Center firstly appeared in the 1970s in China's Taiwan region. The earliest teahouse in mainland was the "Lao She Teahouse", founded in 1988 and known as "folk art window". Since then, a number of Tea Culture Centers have emerged throughout the country and flourished in the large and medium-sized cities in the ascendant. Tea Culture Center is the combination of tea and art, and it has three characteristics:

First, the Tea Culture Center is mainly for drinking tea, but the owners emphasize cultural atmosphere particularly, besides external environment, they pay more attention to internal cultural flavor. In addition to famous calligraphy and painting, folk arts and crafts, antiques and valuable tea and tea sets, they value the traditional virtues of the Chinese nation manifested in elegant tea performances.

Second, in addition to providing a place for negotiating business, making friends by tea, the Tea Culture Center aims at forming a small-scale cultural exchange place for people to communicate on spiritual level, which is similar to literature and calligraphy salon.

Third, people coming here value social responsibility. The Tea Culture Center is no longer a place for people in various trades to gather while most of them come from the cultural, academic and business circles.

The operating principles for Tea Culture Center are: restoring and promoting the Chinese tea culture and inspiring the national spirit; Researching and popularizing of tea to provide people with a high level of spiritual enjoyment and adjust physical and mental state; making tea popularized and boosting tea industry; advocating tea values and improving social trends to facilitate international cultural exchanges.

Tea Culture Center is different from teahouse, it is the product of new society and new stage. It also needs time to prove whether the Tea Culture Center can replace teahouse.

\section{THE FunCTION EVOLUTION OF TEAHOUSE}

\section{A. The Functions of Teahouse in Traditional Society}

The teahouse in the traditional society was the place where people killed their leisure time. During the Republic of China, Huang Yanpei visited to Chengdu and wrote a limerick 
describing Chengdu people's daily leisure life. Two of which are: a person counted the blocks on the street to spare time while two people went into the tea shop sitting from morning till night. [5] At that time, people who forced to make a living or whose ancestors had been doing this would open the teahouse. They usually say fine words, hire one or two partners or family members to help them. The scale of teahouse is not large and the price of tea is cheap.

Since the eastern and western Jin dynasty as well as Northern and Southern Dynasties, China has had social etiquettes like "offering tea to guests" and "making friends by tea". In traditional society, most people drink tea when they are boring, they order a bowl of tea when they have nothing to do and drink for a long time. Twos and threes sat around a table, eating melon seeds and drinking tea, meanwhile they talk whatever they like freely, comfortable and leisure.

In the Teahouse by Lao She, there is a scene that Liu pock sells women and he sells Kang Shunzi to a eunuch. There is also the phenomenon that Liu pock sells foreign watch to Song Erye. From these we can see that some people regard the teahouse as a trading place. [6] However, trade at that time was limited and the process was relatively private and informal.

Another function of traditional teahouse is to resolve conflict. In traditional society, in order to solve conflicts among people, they usually go to teahouse to seek support. This is "drinking comment tea" or "discussing totally is ok". There is no forever obstacle in the world so they forgive and forget.

\section{B. The Functions of Teahouse in Modern Society}

1) An extension of modern living space: Seeing from the real life, in the process that the society develops from the food and clothing to the well-off being, the majority of residents still live in a relatively small place, so people need some space to extend living space. People need a safe and wellconditioned public place especially for friends' party, business communication and lover's date. Modern teahouse in cities satisfies people's demand on the public space because of its comfortable environment, complete facilities and superb service.

2) First choice for healthy entertainment: Teahouses are greatly different from professional performance places when people hold drama and music performances, due to lighting, sound and seat settings, so customers would not like to come here to see such performances. Only folk art, storytelling as well as the performance of small indoor musical instruments, whose effect will not be affected by the limited conditions would become suitable for teahouse.

However, with the continuous development of society, many people are not satisfied with just being audiences in culture and entertainment, but participating actively. Such as calligraphy and painting, opera cymbals, costumes, antique appreciation and so on. Teahouses can play a good role in these areas organizer.

3) An important platform for communication and exchange: For thousands of years, people have been able to survive under a variety of pressures, thanks to such a survival strategy, that is, trying to alleviate the pressure of work and life in a variety of ways. Now due to competitive society and big pressure from work and life, people still need to get the basic needs of life through their own efforts, but the difference is that people begin to seek a place to release pressure and communicate with each other outside the work to form another lifestyle. The teahouses provide such places for people. When getting off work, they call on a few friends to the teahouse, drinking tea and listening to music while chatting to relax mood and enjoy the wonderful life

\section{UniQue TEAHOUSE CUlture OF OUR NATION}

\section{A. Teahouse in Beijing}

There are various teahouses in Beijing. In terms of their formation, teahouses can divide into brick teahouse, green teahouse, storytelling teahouse, Acacia catechu shops and wild teahouse. There are many storytelling teahouses in Old Beijing. In such teahouses, people come here mainly to listening to storytelling while drinking tea. In storytelling teahouse, the owners sell green tea before storytelling and supply water and rest places for pedestrians. When storytelling begins, customers listen to books over drinking tea so the owners would no longer receipt the general guests. Famous storytelling teahouses stress layout, the owners match rattan chairs with rattan tables and wooden chairs with wooden tables, they sometimes hang some calligraphy and painting on the wall to create the atmosphere of listening to books. Storytelling teahouses around platform bridges are mainly provide Chinese folk art forms performances such as the plum flower drum, story-telling in Beijing dialect with drum accompaniment, North plate drums, Tangshan big drum and lihua dagu (an entertainment in which the singer sings folk songs to the accompaniment of drum by herself). There are also many green teahouses in Beijing. The environment theme is prominent. There are usually square tables and wooden chairs with elegant and brief furnishings. Green teahouses provide covered tea. In spring, summer and autumn, the owners set shade-shed outside the door or inner courtyard, some odd customers sitting here. While inside the house are regular customers and comfortable seats. Most of customers of green teahouse are the old. An special teahouse in Beijing is Chess teahouse, people can play chess while drinking tea. Beijing people love to go on trips. They are on outings in spring, see lotus in summer, look red leaves in autumn and appreciate Xishan snow in winter, so the wild teahouses appear in the suburbs. All the brick teahouses in Beijing use tureen, healthful and heat retaining. Beijing people pay attention to manners. When drinking tea, they are impolite to make mouths exposed, so the bowl cover is used to dial the tea before drinking and cover the mouths when drinking. According to the service facilities, there are red furnace teahouses, Uovo teahouses and Banhu teahouses.

\section{B. Teahouse in Hangzhou}

Teahouse in Hangzhou has a long history. Historical books such as Mengliang Record written by Wu Zimu of the Southern Song Dynasty and The Scholars by Wu Jingzi of the 
Ming Dynasty have a very detailed record about it. Reviewing the history of ancient and modern Hangzhou, we can find that the fate of teahouses are closely linked to the rise and fall of Hangzhou

According to relevant data records, there are 81 teahouses in Hangzhou city center in 1959. After the "cultural revolution", there are only 21 teahouses and 24 scenic teahouses in the early 1980s. According to the data provided in 2015 , there are more than 1,500 teahouses of different sizes in Hangzhou.

\section{Teahouse in Tianjin}

Tianjin people have special feelings for teahouse because many of them grow up with listening to cross talk accompanied by their parents. Therefore, the Strong mass base is the key to tea culture taking root in Tianjin continuity. In addition, Tianjin audiences have appreciation of the highest level over the country in the opera. There is a saying that learning in Beijing and being popular in Tianjin in opera field. That is, the actors wanting to be popular must receive the test of Tianjin people. If they agree, the actors are qualified. Previously, Guo Degang has performed in Tianjin before being famous. It is said that he performs very well and return to the field several times to give performance.

Moreover, the Tianjin audiences have greater tolerance and acceptance for new art forms than any other places. During the period of the Republic of China, Mr. Mei Lanfang performed a new program the Heavenly Maids Scatter Blossoms in TianJin. Both costumes and singing were nowhere to find on Peking Opera stage, but he still conquered the audience by his artistic expression in Tianjin and brought down the house. It can be said that the reason why teahouse in Tianjin is different from the rest of the country is that the audiences account for a large part.

\section{Teahouse in Sichuan}

Teahouse in Sichuan has a multi-functional function. It integrated political, economic and cultural functions together, playing a role to remedy defects much for the community. Although lacking of some elegance, it fully manifests the cultural and social functions of tea, which is a major feature of Sichuan teahouse culture.[7]

Teahouse in Sichuan has been extremely prosperous. Whether it is scenic spots, or downtown streets, we can see the teahouse with local characteristics everywhere. Prices are cheap in these teahouses with courteous service so customers only order a cup of tea and some snack and sit half-day. In conversation with friends and family, the tea culture of Bashu appeared incisively and vividly. Once people of the eastern region came to Chengdu and wondered: "Chengdu people how can be so leisure, they have no work to do?" People sometimes may think "Chengdu people out of Sichuan bear hardships and work hard while those in Chengdu are leisure". Actually, not only people in Chengdu, but also people in whole Sichuan live comfortably. They are not doing nothing all day, it should be said they know how to live. Their lives are actually busy, but they know how to steal a half-day to leisure and know what kind of life they need to relax themselves. Sichuan people are very hard-working, no matter what their job is, to do manual labor or mental workers, they have made certain achievements of all walks of life over the country and enjoyed high praise. So we cannot say that the way of life in Sichuan is kind of lazy, in fact, it is a leisure life style, which is particularly helpful to balance fast-paced style in our modern life.

\section{CONCLUSION}

China is hometown of tea and birthplace of tea culture. The history of discovery and use of tea has been 5,000 years. It is enduring and spread all over the world. China has a long history of teahouse culture. Tea stalls had appeared in the Jin Dynasty, to the Tang, Song, Ming and Qing Dynasties, a wide range of teahouse gradually developed. After a special historical period of the republic of China, the teahouse turns forward in the twists. After the founding of our country, the teahouse has developed unprecedentedly, especially after the reform and opening up, teahouse culture is inherited and spread better, the concept of leisure has gradually penetrated into the teahouse culture.

The development of the teahouse will be more specialized, characteristic in the future reflecting the different characteristics of each teahouse. With the development of society and the improvement of living standards, the requirements on the teahouse are diversified. The teahouse will continue to meet the needs of people, develop a wide range of teahouses. After washing of a long history and development of generations, the teahouse will play a better function for people's life, teahouse and tea culture will become the unique landscape of our society.

\section{REFERENCES}

[1] Lu Yu. Tea Ching[M]. Beijing: China Textile \& Apparel Press, 2006

[2] Lin Qianliang. Shennong Bencao Jing Uncollected tea[J]. Chinese tea. 2013(03)

[3] Wenjing, Xie Kangyou. Jiangnan tea culture of a long history[J].When the Chinese publication, ,2014,07:61.

[4] Song Shilei. Study on Tea Culture in the Tang Dynasty[D]. Wuhan University, 2013.

[5] Zhao Tiantian. The evolution of the teahouse function[J]. Guangdong tea. 2005. Page 32-34

[6] Laoshe. Teahouse[M]. Tianjin: Tianjin Peoples Publishing House. 2006.

[7] Wang Zhenheng, Wang Yun, Zhu Shiying. Sichuan famous tea and Sichuan teahouse culture[J]. Agricultural Archa. 2000(02). 